\title{
Overview and outcomes of the OECD/NEA benchmark study of the accident at the Fukushima Daiichi NPS (BSAF), Phase 2 - Results of severe accident analyses for unit 3
}

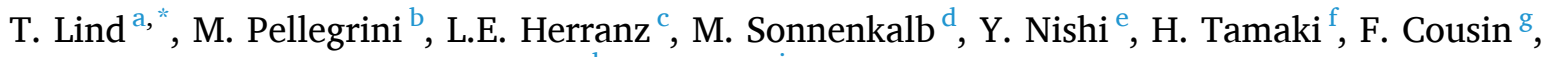 \\ L. Fernandez Moguel ${ }^{\mathrm{a}}$, N. Andrews ${ }^{\mathrm{h}}, \mathrm{T}$. Sevon ${ }^{\mathrm{i}}$
}

${ }^{\text {a }}$ PSI, Switzerland

${ }^{\mathrm{b}}$ IAE, Japan

c Ciemat, Spain

${ }^{\mathrm{d}}$ GRS, Germany

e CRIEPI, Japan

f JAEA, Japan

${ }^{\mathrm{I}}$ IRSN, France

${ }^{\mathrm{h}}$ SNL, USA

${ }^{\mathrm{i}}$ VTT, Finland

\section{A R T I C L E I N F O}

\section{Keywords:}

Fukushima

Unit 3

OECD/NEA BSAF project

Accident analysis

Fission products

\begin{abstract}
A B S T R A C T
This is the third part of the three part paper describing the accidents at the Fukushima Daiichi nuclear power station as analyzed in the Phase 2 of the OECD/NEA project "Benchmark Study of the Accident at the Fukushima Daiichi Nuclear Power Plant" (BSAF). In this paper, we describe the accident progression in unit 3 . Units 1 and 2 are discussed in parts 1 and 2 of this series of papers.

In the BSAF project, eight organizations from five countries (CRIEPI, IAE, JAEA and NRA, Japan; IRSN France; PSI, Switzerland; SNL, USA; VTT, Finland) analyzed severe accident scenarios for Unit 3 at the Fukushima Daiichi site using different severe accident codes (ASTEC, MAAP, MELCOR, SAMPSON, THALES). The present paper for Unit 3 describes the findings of the comparison of the participants' results against each other and against plant data, the evaluation of the accident progression and the final status inside the reactors. Special focus is on the status of the reactor pressure vessel, melt release and fission product release and transport. Unit 3 specific aspects, e.g., the complicated accident progression following repeated containment venting actuations and attempts at coolant injection at the time of the major core degradation, are highlighted and points of consensus as well as remaining uncertainties and data needs will be summarized. Fission product transport is analyzed, and the calculation results are compared with dose rate measurements in the containment. The release of I-131 and Cs-137 to the environment is compared with analysis conducted using WSPEEDI code.
\end{abstract}

\section{Introduction}

The Great East Japan earthquake occurred on March 11th, 2011 at 14:46 (Japan time zone). Scram successfully started at 14:47 in all three operating units $1-3$ followed by system isolation by the main steam line valve. From TEPCO's observation of the plant's operation status, the main safety systems are assumed to have maintained their operability after the earthquake. The earthquake was followed by a number of tsunami waves about 45 min later which, by reconstruction through videos and onsite post-measurement, is estimated to have reached a height of $14 \mathrm{~m}$ causing a large-scale disaster in the Pacific Ocean coastal areas (TEPCO, 2014). The intensity index of the wave was designated as 9.1 using the international index indicating the scale of tsunami. It was the fourth largest tsunami ever observed in the world and the largest ever recorded in Japan. The result for Units 1 to 3 was the loss of the ultimate heat sink, loss of measurement systems and a remarkable difficulty or even total inability to operate the reactor safety systems to guarantee core cooling.

\footnotetext{
* Corresponding author.

E-mail address: Terttaliisa.lind@psi.ch (T. Lind).
} 
At the time of the tsunami arrival, reactor in unit 3 was in cold shutdown with the reactor core isolation cooling (RCIC) in operation and the safety relief valves (SRV) controlling the reactor pressure. The tsunami waves caused all the AC power supplies to be lost but DC power remained available thereby providing a possibility for coolant injection into the reactor for more than $30 \mathrm{~h}$.

Detailed account of the accident is given, e.g., by Yamanaka et al. (2014), and further analysis of the unit 3 by e.g., Cardoni et al. (2014), Pellegrini et al. (2014), Robb et al. (2014), Yamanaka et al. (2014) and Fernandez-Moguel et al. (2019).

The OECD/NEA project "Benchmark Study of the Accident at the Fukushima Daiichi Nuclear Power Station (BSAF)" was established in 2012. One objective of the project was to analyze the accident progression using severe accident codes and methods typically applied by the partners, to compare the results acquired with different codes, and to consider latest information on the status of Units 1 to 3 of the Fukushima Daiichi nuclear power plant (NPP). In the BSAF Project Phase 2, the analysis time was extended from about 6 days analyzed in Phase 1 to up to 3 weeks from the initiation of the accident. In addition, more emphasis was given to the release and transport of fission products while at the same improving the thermal-hydraulic representation of the accident progression.

In this paper, the findings of the comparison of the participants' results for Unit 3 against each other and against plant data, the evaluation of the accident progression and the final status inside the reactor are discussed. Special focus is on reactor pressure vessel (RPV) status, melt release and fission product (FP) behavior and release. Unit 3 specific aspects are highlighted, and results based on the eight sequence analyses will be summarized. Finally, the remaining uncertainties and data needs will be discussed. The results for Units 1 and 2 have been discussed by Herranz et al. (2020) and Sonnenkalb et al. (2020). An overall summary and conclusions of the project are provided elsewhere (Pellegrini et al., 2019a).

\section{Analysis methods}

In the BSAF project Phase 2, Unit 3 analyses were carried out by eight partners using five different severe accident codes, Table 1 . No recommendations on severe accident codes to be used were given in the project. The codes normally used for severe accident analyses in the participating organizations were applied. The input models for the calculations were developed to a large extent in the Phase 1 of the BSAF project based on a common data base. The models were refined and modified in the Phase 2 based on the experience from analyses in Phase 1 with the aim of analyzing the accident for the duration of three weeks with a special focus on fission product transport. Input models for MELCOR, SAMPSON, and THALES/KICHE are described by Cardoni et al. (2014), Fernandez-Moguel et al. (2019), Pellegrini et al. (2014), and Yamanaka et al. (2014), respectively. Detailed description of the input models is beyond the scope of this paper, and can be found in (Pellegrini et al., 2019b).

Table 1

Participants and codes employed for Unit 3 analyses.

\begin{tabular}{llll}
\hline & Organization & Country & Code \\
\hline 1 & CRIEPI & JAPAN & MAAP \\
2 & IAE & JAPAN & SAMPSON-B 1.4 beta \\
3 & IRSN & FRANCE & ASTEC V2.0 rev3 p1 \\
4 & JAEA & JAPAN & THALES \\
5 & NRA & JAPAN & MELCOR 2.1-7317 \\
6 & PSI & SWITZERLAND & MELCOR 2.1-4206 \\
7 & NRC/DOE/SNL & U.S.A & MELCOR 2.1-5864 \\
8 & VTT & FINLAND & MELCOR 2.2-9607 \\
\hline
\end{tabular}

\section{Latest plant investigations}

Information about the status of the reactor and core in unit 3 was collected by muon measurements and two series of containment investigations. Muon measurements were used to estimate the amount of material present in the different parts of the reactor pressure vessel as compared to the situation before the accident. Containment investigations provided photographic and video evidence of the status of the structures and material present in the containment drywell.

The muon measurement device was installed to allow investigation of the reactor pressure vessel from the lower head to the top of the core region. The measurement was started in May 2017 and lasted for several months. The evaluation of the muon data shows that the amount of highdensity material in the core is lower than for an intact core. It seems that the bulk of the fuel and structures have moved to the lower parts of the RPV. The amount of high-density material beneath the RPV bottom is higher in some locations compared to the mass estimated to have existed before the accident. The data indicate that some fuel debris remains in the core and in the lower head of the RPV. The extrapolated values estimated by TEPCO give as approximated values 30 ton of debris remaining in the core region and approximately 90 ton in the bottom of the RPV. The mass of debris released from the reactor vessel to the containment was not estimated based on the muon measurements.

Robot investigations of the containment drywell were started in unit 3 in 2015 and continued until 2018 reaching areas inside the pedestal. The image given by the robots is very heterogeneous showing relatively large areas of undamaged structures close to the reactor vessel bottom, e.g., control rod drives appear mainly in place, but at the same time, large amounts of material are seen on the pedestal floor. The images show even large, relatively undamaged fallen objects, such as control rod guide tubes (CRGTs) and control rod velocity limiters (TEPCO web site). This indicates that the size of the vessel failure should be larger than the diameter of the CRGT. The material on the pedestal floor is very unevenly distributed with the highest layers reaching approximately 3 $\mathrm{m}$ from the floor, and the layer being considerably lower in other areas. The material on the pedestal floor has mainly a sand-like appearance with larger pebbles included with some of the fallen objects partly covered by the rubble.

\section{Thermal-hydraulic and core degradation analyses}

Unit 3 had DC power after the tsunami, and consequently, it is the unit which has the largest amount of measured data available, e.g., water level and pressure of the reactor pressure vessel, as well as the pressure and temperature of the primary containment vessel (PCV) are available for long periods of time. Several containment vent actuations were carried out and coolant was injected by different means but not continuously. The timings of the coolant injection to the reactor as well as containment vent events were recorded by the operators and used by the analysts as boundary conditions. It should be noted that even though the approximate timing of the coolant injections is known, the amount of water reaching the reactor is uncertain. Similarly, even though the operators recorded vent actuations, it has not been confirmed that all those actuations were fully successful.

In this work, different analyses use different assumptions regarding the quantity of water reaching the reactor in an attempt to reproduce the main accident signatures, such as the RPV and PCV pressure, water level, and the timing of the hydrogen explosion. It should also be noted that even though plant data measurements are available, there is some uncertainty in the reliability of the measurements as the instruments were operating outside of their design range, sometimes for longer periods of time. This was taken into account by the analysts when comparing the calculation results with the plant data. For more information about the detailed accident progression, see (Pellegrini et al., 2019b) and unit 3 specific references given above. 


\subsection{Early accident phase until reactor de-pressurization}

For the first $20 \mathrm{~h}$ after the accident initiation, the reactor in unit 3 was cooled by RCIC, the pressure was regulated by SRVs, Fig. 1, and the water level in the reactor stayed relatively constant at a high level. The containment pressure, Fig. 2, increased continuously. The pressure increase in the containment was faster than the first simulations indicated. Later analyses showed that the pressure increase was likely due to stratification in the suppression pool leading to high pool surface temperature and to reduced steam condensation of the SRV and RCIC release gas. After about $20 \mathrm{~h}$, RCIC stopped automatically due to high pressure in the suppression pool. Due to this, the water level in the reactor started to decrease. High pressure coolant injection (HPCI) system started after about one hour due to the low water level in the reactor. After HPCI operation started, the water level in the reactor increased again whereas the pressure in the reactor decreased due to large amount of water injection. The analyses indicate that HPCI performance started to degrade at around $30 \mathrm{~h}$, and it was finally manually stopped at $36 \mathrm{~h}$. Most of the analyses could reproduce the RPV and PCV pressure trends in a satisfactory way during this time.

After coolant injection by HPCI stopped, there was a period of some $10 \mathrm{~h}$ with no coolant injection into the reactor. During this time, the water level in the reactor dropped to below the bottom of active fuel (BAF), Table 2, and the reactor pressure increased rapidly. Most of the analyses show that major core degradation started during this time with accompanied hydrogen production, Fig. 3. The reactor pressure reached the set point of the SRVs, and after several hours of high RPV pressure, reactor was depressurized by the automatic depressurization system (ADS) at $42 \mathrm{~h}$. This led to a rapid increase of the containment pressure, Fig. 2.

\subsection{From reactor depressurization to hydrogen explosion}

The period after reactor depressurization at $42 \mathrm{~h}$ until a hydrogen explosion took place in unit 3 reactor building at $68 \mathrm{~h}$ was characterized by several actuations of containment venting and coolant injection with the reactor water level staying at a low level, Fig. 4. There were four measurement ranges for main water level indicators: the wide range, narrow range, fuel range and shutdown range. Two of them were used to support the analysis in the BSAF project: the fuel range covering the level from the bottom of active fuel to about the top of the shroud, and the wide range showing the water level above the top of active fuel. More details about the water level measurements are provided in (The Damage and Accident Responses at the Fukushima Daiichi NPS and the Fukushima Daini).

As shown by most of the analyses, major core degradation and core slumping events took place during the time from reactor depressurization to the hydrogen explosion leading eventually to failure of the reactor pressure vessel. The timing and mode of the reactor pressure vessel failure given by different analyses are shown in Table 3. It is seen that the timing of the vessel failure has quite some uncertainty depending on the boundary conditions and codes used. Comparison of the fission product behavior results with the containment dose rate measurements later in this paper shows that the very early vessel failure is unlikely because this would result in much higher dose rate in the containment than measured. Similarly, very late vessel failure would be unlikely due to resulting low dose rate in the containment.

\subsection{Late accident progression and the status of the core at the end of the analysis}

After the hydrogen explosion in the reactor building, the containment pressure remained above $0.2 \mathrm{MPa}$ until about $130 \mathrm{~h}$, decreased, and then increased again until about $200 \mathrm{~h}$, Fig. 5 . This was partly due to further hydrogen generation by the corium and metallic structures oxidation in the containment as shown by several analyses, Fig. 6, and partly due to steam generation. Coolant was injected into the reactor almost continuously after the hydrogen explosion, and this resulted in considerable steam generation. The reason for the pressure increase after $150 \mathrm{~h}$ is not conclusively resolved. Due to the coolant injection, several calculations showed that the water level in the containment reached the main steam line penetration in the drywell at the end of the calculation. The containment pressure trend at this time is reproduced relatively well by most of the analyses.

At the end of the analysis, most calculations predict a large mass of debris discharged into the containment followed by continuous molten core-concrete interaction (MCCI), Fig. 7 and Table 4. Three calculations show a smaller amount of material released to the containment. The

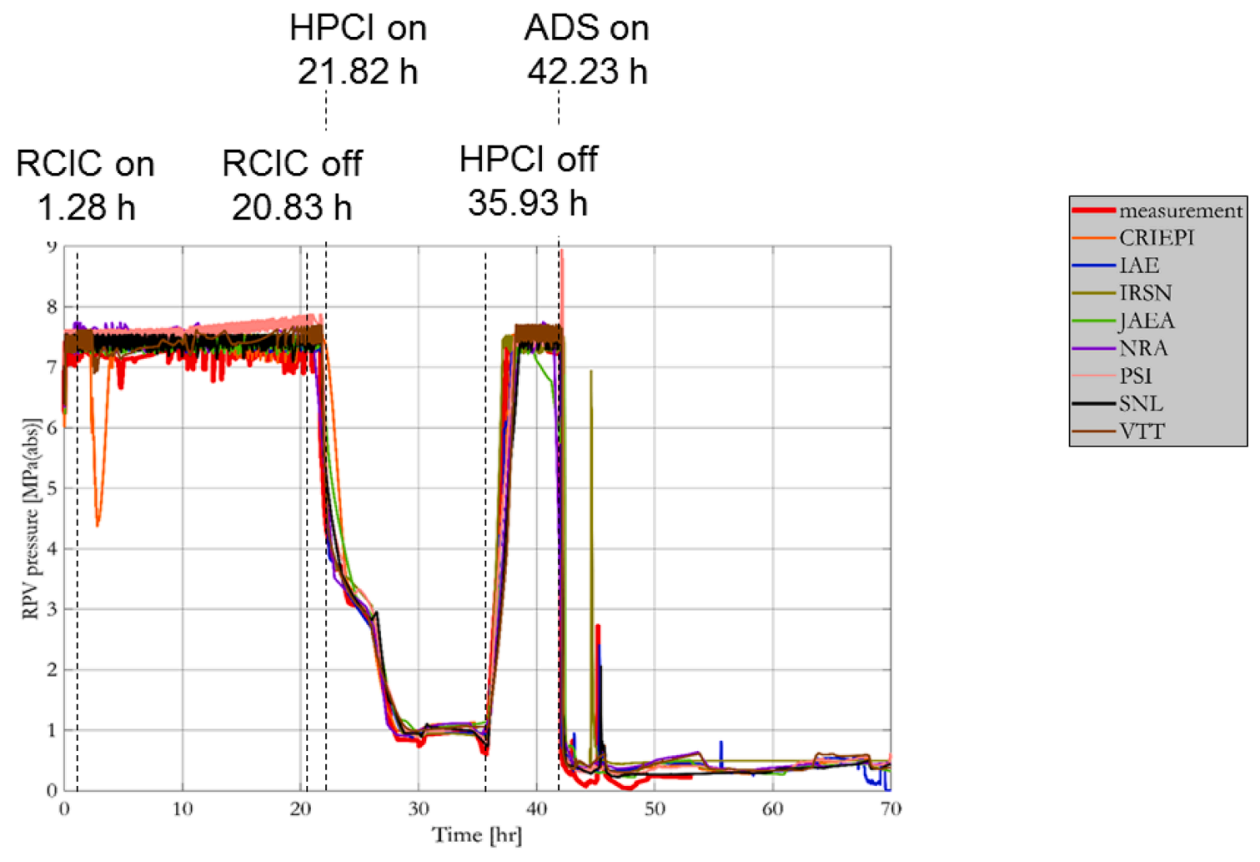

Fig. 1. RPV pressure. 

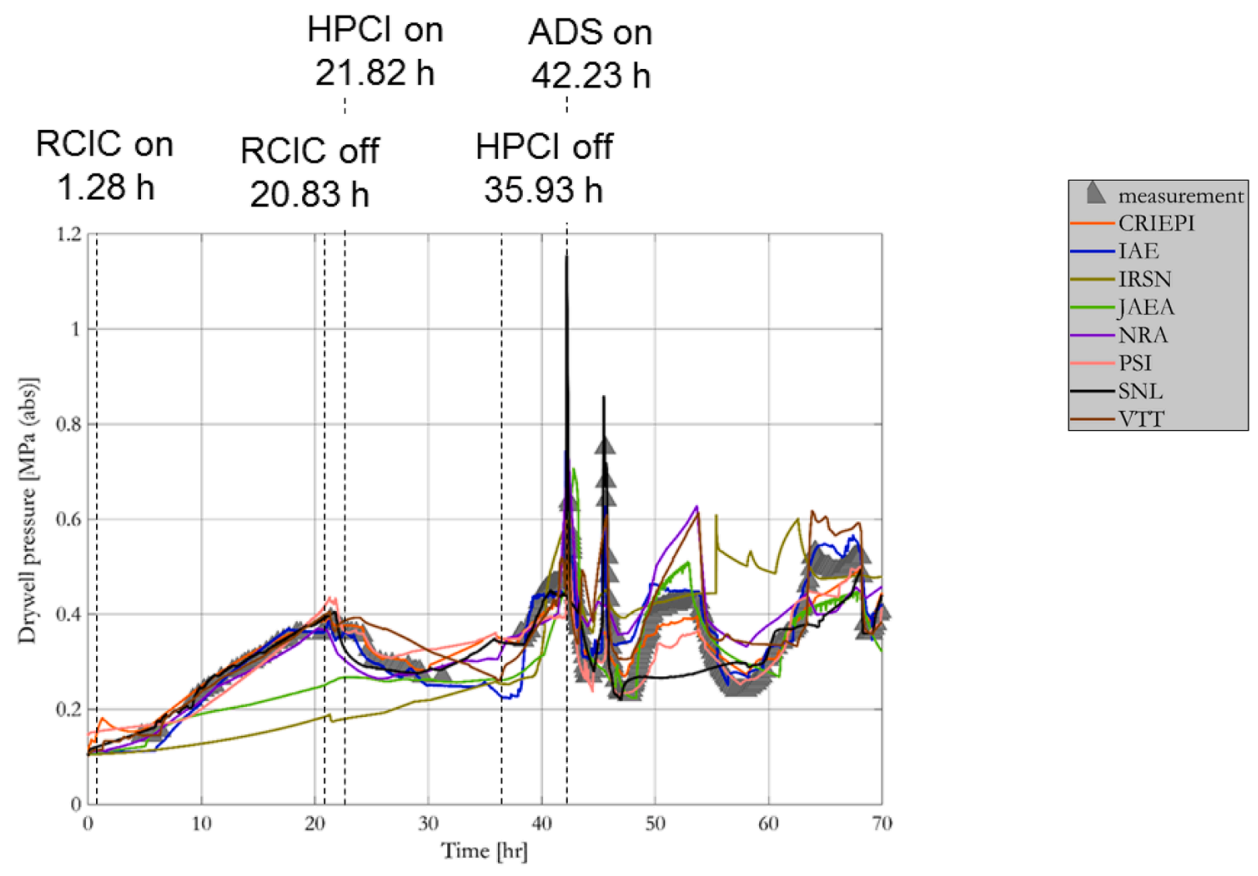

Fig. 2. Drywell pressure.

Table 2

Time to reach BAF in comparison with the measurement (time in hours after SCRAM).

\begin{tabular}{|c|c|c|c|c|c|c|c|c|}
\hline Measured & CRIEPI & IAE & IRSN & JAEA & NRA & PSI & SNL & VTT \\
\hline 40.8 & 42.3 & 40.2 & 40.5 & 39.8 & 41.6 & 42.1 & 42.0 & 40.9 \\
\hline
\end{tabular}
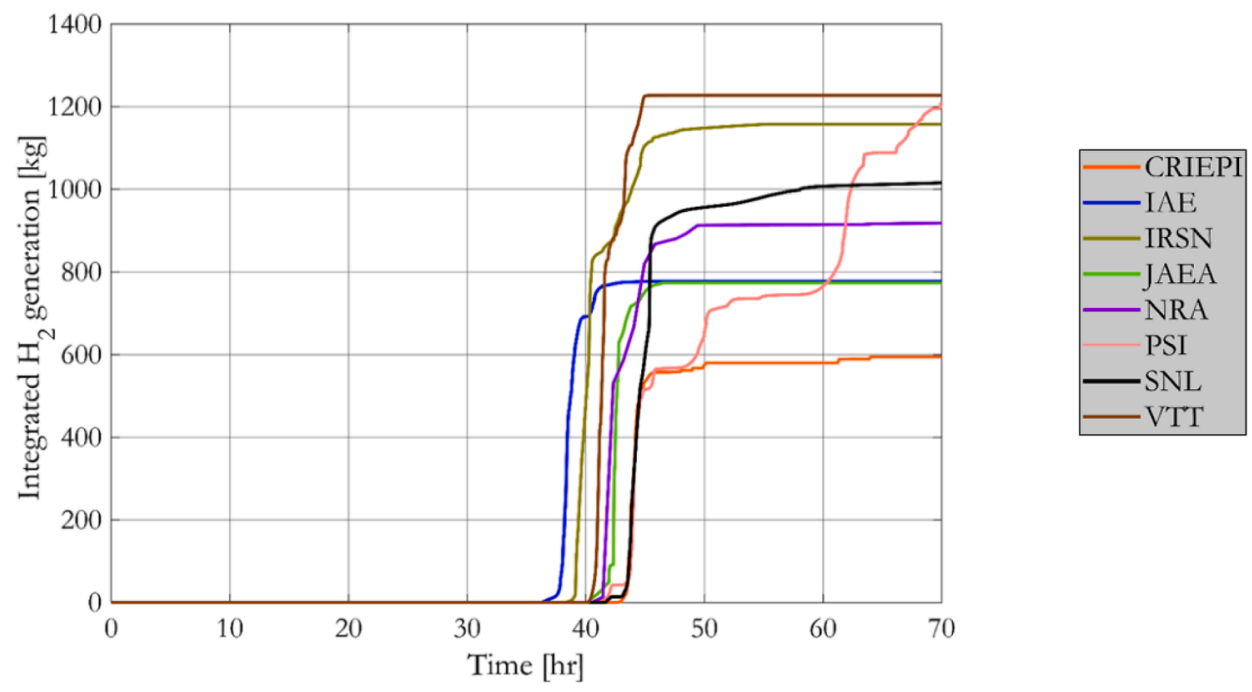

Fig. 3. In-vessel hydrogen generation.

variation in the results by different analyses is large regarding both the timing and the magnitude of the corium release from the reactor pressure vessel to the containment. All the calculations except for one show that molten core-concrete interaction (MCCI) started once the corium was released to the containment floor.

The latest investigations in unit 3 containment by TEPCO (2017) indicate that the debris mass in the containment is likely closer to the higher values given by the analyses than the lower ones. The appearance of the debris in the containment is porous which might indicate that not all the material in the containment has been molten and that the molten core-concrete interaction might have been limited. However, it should be noted that the morphology of the corium and other materials in the containment should have undergone considerable changes during the years the materials have been exposed to chemical reactions and high dose rates in an under-water environment, and therefore the morphology observed now might not be representative of the materials during the accident. 

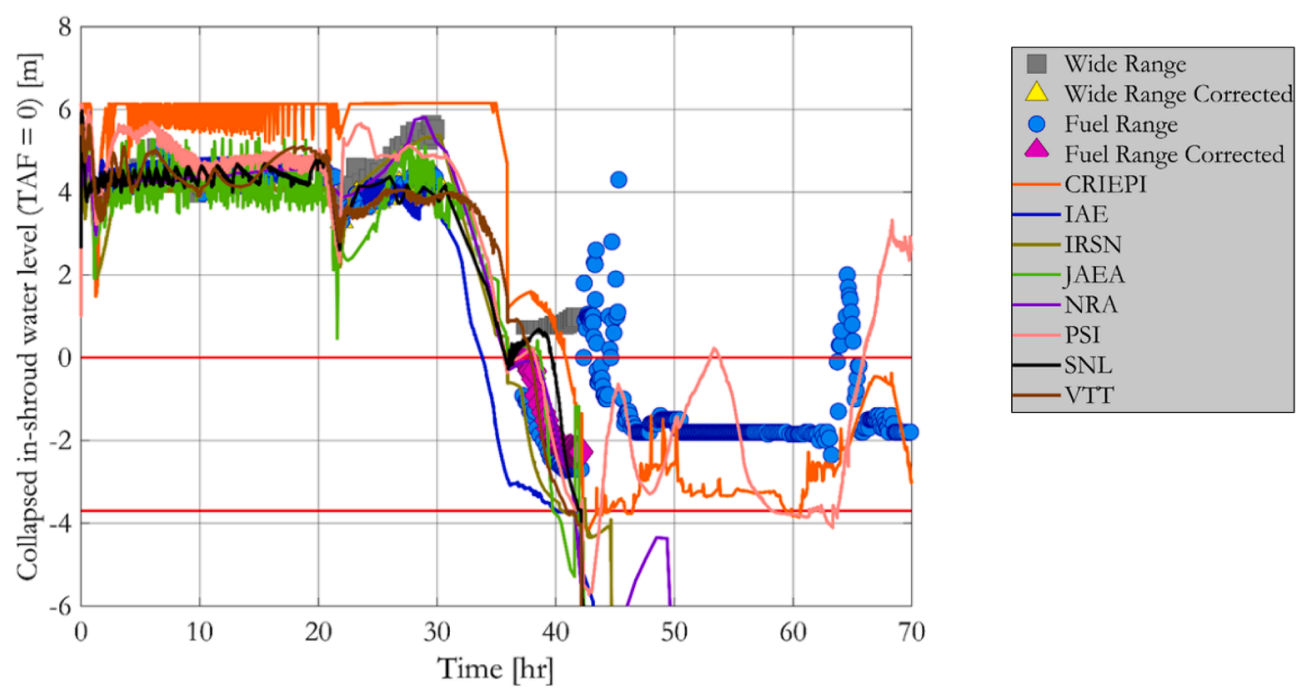

Fig. 4. RPV water level until the hydrogen explosion.

Table 3

Lower head failure time (hours after SCRAM) and mode of failure.

\begin{tabular}{|c|c|c|c|c|c|c|c|c|}
\hline & CRIEPI & IAE & IRSN & JAEA & NRA & PSI & SNL & VTT \\
\hline Time of failure & 102.0 & 55.2 & 55.4 & 46.5 & 49.4 & 73.1 & 58.0 & 43.3 \\
\hline Mode of failure & Penetra-tion & Creep & Creep & Vessel melt & Penetra-tion & Penetra-tion & User specified & Penetra-tion \\
\hline
\end{tabular}
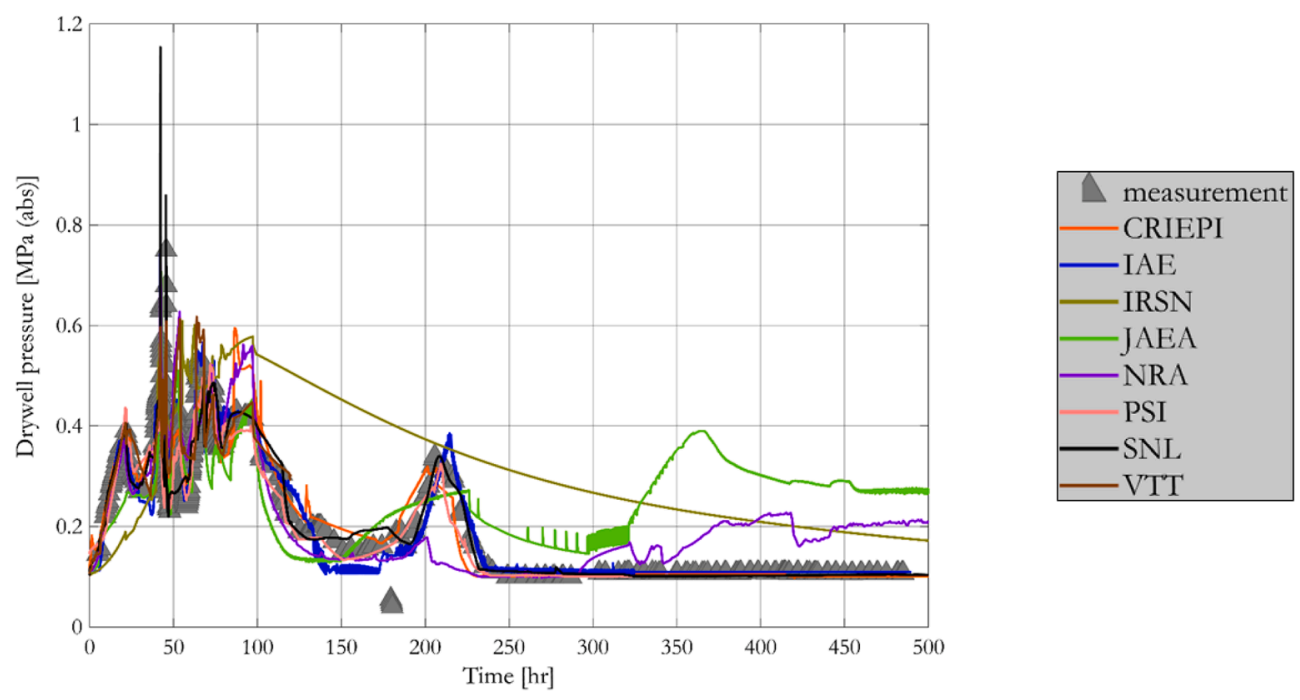

Fig. 5. Containment pressure after the hydrogen explosion in unit 3.

\section{Fission product release and behaviour}

The release and transport behavior were calculated for a large number of fission products. For simplicity, in the following, we concentrate only on cesium and iodine as the most volatile ones after noble gases. We track the release of cesium and iodine from the fuel, transport from the RPV to the PCV, and release to the environment. Finally, we compare the environmental release fraction given by the accident analysis codes to those estimated by reverse methods which are based on measurement and distribution of the fission products in the environment.

A critical factor when calculating the fission product release to the atmosphere is the transport path from the RPV to the PCV, on to the auxiliary buildings and finally to the environment. In a BWR, fission product scrubbing in the suppression pool is an efficient retention mechanism [e.g., Rýdl et al., 2018]. This reduces the potential release of activity to the atmosphere as long as the main transport path of the gases from the RPV is through the suppression pool. Consequently, one of the critical issues to consider when looking at the fission product transport is to determine whether the fission products were transported to the suppression pool.

This was the case in unit 3 as long as the RPV was in-tact and the SRVs were controlling the pressure in the RPV. In this case, the steam carrying the fission products was released from the RPV to the suppression pool through the SRV lines, and the spargers distributed the gas in the suppression pool securing efficient scrubbing of the fission products. However, a fraction of the fission products was not scrubbed in the suppression pool, and that was then available for release to the 

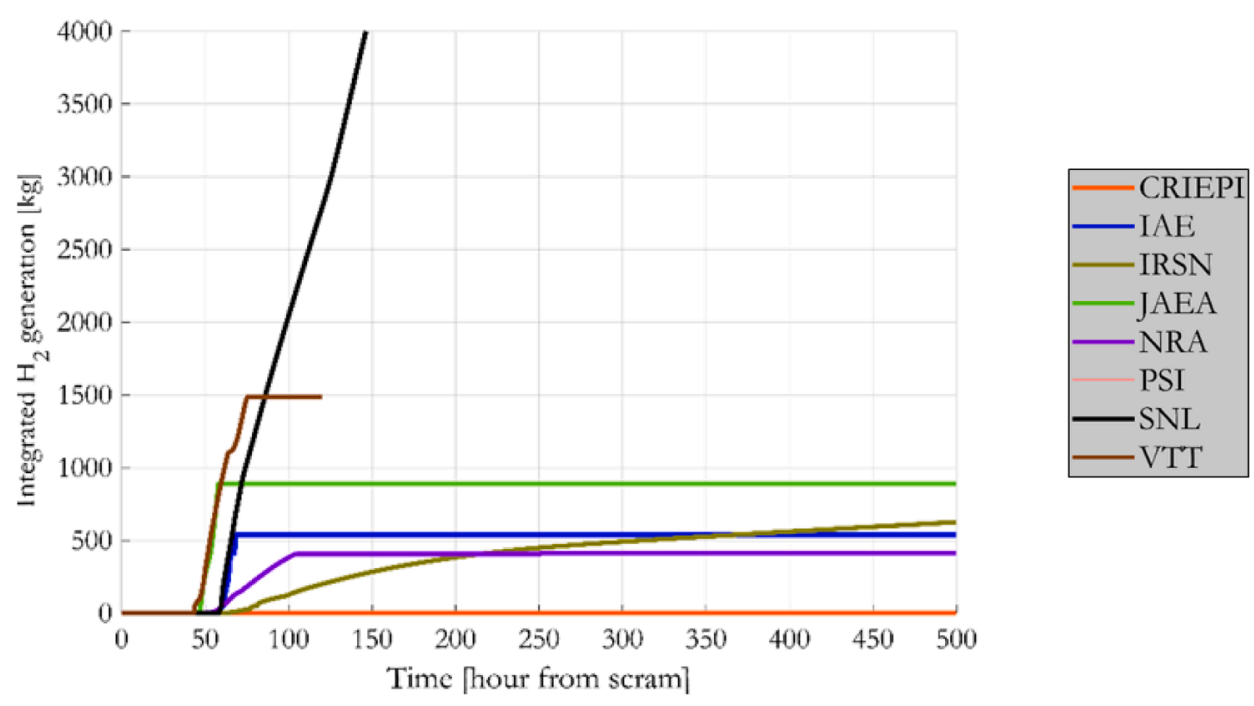

Fig. 6. Ex-vessel hydrogen generation.

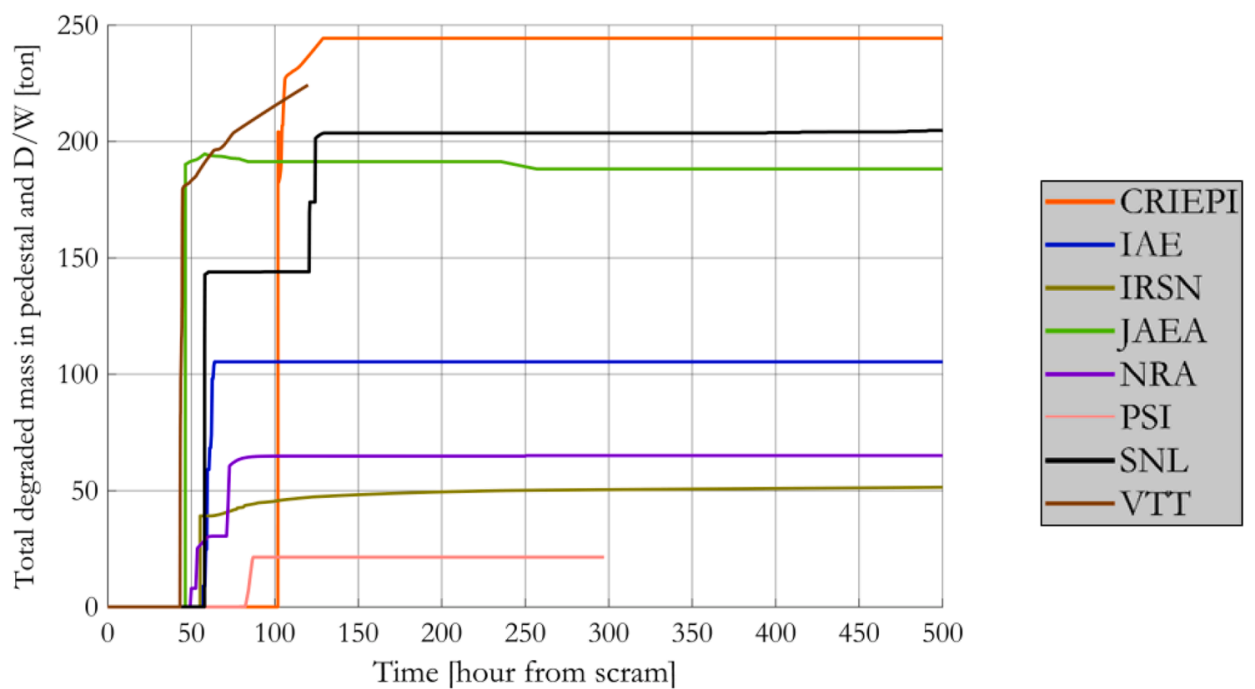

Fig. 7. Debris mass in the containment.

Table 4

Total debris mass released from the reactor pressure vessel to the containment.

\begin{tabular}{lllllllll}
\hline & CRIEPI & IAE & IRSN & JAEA & NRA & PSI & SNL & VTT \\
\hline Mass [ton] & 244 & 105 & 51 & 188 & 65 & 21 & 205 & 224
\end{tabular}

environment during containment venting from the gas space of the suppression chamber.

Based on the thermal-hydraulic analysis, some of the analysts assumed that there were leakages which allowed the gas with the fission products to be transported from the RPV to the containment without being scrubbed in the suppression pool, Table 5. It is seen that two

Table 5

Assumed leakages and the start time (hours after SCRAM) from RPV into PCV.

\begin{tabular}{|c|c|c|c|c|c|c|c|c|}
\hline & CRIEPI & IAE & IRSN & JAEA & NRA & PSI & SNL & VTT \\
\hline MSL leak & & & & & & & 42.3 & \\
\hline SRV leak & & & & & 42.2 & & & \\
\hline Pump seal leak & & & & 5.0 & & & & 6.33 \\
\hline TIP leak & & & & 39.8 & 41.9 & & & \\
\hline
\end{tabular}

analyses assumed an early outflow from the RPV by a pump seal leakage. Other analyses showed leakages at around the time the core degradation started in unit 3. One analysis indicated reactor de-pressurization by a main steam line failure and subsequent release of fission products to the drywell.

A new transport path for the fission products was opened once the reactor pressure vessel lower head failed. In this case, the gases were released from the RPV to the containment drywell without being scrubbed in the suppression pool.

Once in the drywell, the fission products may be released to the reactor building if the containment integrity is compromised. In this work, all the analyses assumed that once the containment pressure increased to a certain level, this level being slightly different for different calculations, the head flange of the drywell would lift opening a gap between the drywell wall and the head flange. The gas in the drywell was released through this opening to a cavity under the operating floor of the reactor building. As the reactor building is not designed as a pressure tight structure, the release to the reactor building was followed by a release to the atmosphere. After the reactor building was destroyed by the hydrogen explosion, no retention of air-borne fission products in the building took place.

Specific to unit 3 was the fact that a fraction of the gas in the 
containment was transported to unit 4 reactor building. Hydrogen explosion took place in unit 4 reactor building about $19 \mathrm{~h}$ after the one in unit 3 . The analysis by TEPCO shows that the hydrogen which caused the explosion in unit 4 was transported from unit 3 through the ventilation channel during venting of the containment of unit 3 (Nozaki et al., 2017). According to the analysis by TEPCO, approximately $20-35 \%$ of the vented gas could have been diverted to unit 4 reactor building during the vent actions. This transport path is not accounted for in the analyses shown in this paper.

\subsection{Fission product release from fuel}

The volatile fission product release is shown to progress rapidly once the core degradation starts, Fig. 8. In overall terms most of the calculations draw the same profile: a fast release, with or without subsequent steps according to core degradation progression, up to getting an asymptotic high value bracketed in between $80 \%$ and $100 \%$ of their respective inventory. The release of volatile fission products from the fuel is practically completed by the time the hydrogen explosion occurred in the reactor building at $68 \mathrm{~h}$.

\subsection{Fission product distribution in the containment}

Large fractions of cesium and iodine were retained in the suppression pool water, Fig. 9, in all the analyses. Some analyses showed also a considerable fraction of cesium and iodine in the water in the drywell, Fig. 10 and Tables 6 and 7, indicating a large amount of water in the drywell. Several calculations showed a large fraction of Cs in the reactor pressure vessel due to deposition of Cs compounds on the reactor walls either by chemi-sorption or by aerosol deposition, Table 6 . Three calculations indicated also a significant fraction of both cesium and iodine in the reactor building. Even though not shown in Table 6, this fraction was calculated to be transported to the reactor building with a water leakage from the containment once the water level in the drywell reached the main steam line elevation.

\subsection{Comparison with the containment dose rate}

The dose rates in the drywell and wetwell (suppression chamber S/C) of the containment were measured during the accident by the containment atmosphere monitoring system (CAMS). Two CAMS each were installed inside the drywell, and outside of the wetwell. In unit 3, CAMS measurement data are available around the time of the hydrogen explosion at $60-70 \mathrm{~h}$, and then again after $150 \mathrm{~h}$. The data were used to compare the timing and magnitude of the measured dose rates with those determined based on the code analyses at the time of the measurements.

For the comparison, the concentration of the different radio-nuclides in the containment as calculated by the severe accident codes needed to be converted to a dose rate considering the specific geometry of the CAMS measurement. Conversion was carried out using conversion factors as described in (BSAF, 2018). The calculated fractions of noble gases, iodine, cesium, and tellurium in the gas phase, liquid phase, and structures in the drywell and in the suppression chamber were used to estimate the dose rate inside the drywell and the suppression chamber, respectively, by using the conversion factors. The conversion factors were obtained using the shield calculation code, QAS-CGGP2 (Sakamoto and Tanaka, 1990). The conversion factors take into account the properties of the individual radionuclides, and the location of the radionuclides in the containment, i.e., water, gas or structure. The individual radionuclides taken into account in the estimation were I-131, I-132, I133, Te-132, Cs-134, Cs-136, Cs-137, Kr-88 and Xe-133. In addition, the decay of the radionuclides over time is taken into account for the estimation of the dose rate. Fig. 11 shows the comparison of the dose rate measured with the CAMS and the estimation of the dose rate for the drywell and the suppression chamber determined by the analyses in this work.

It is seen that the calculations which assume an early and large leakage from the RPV to the drywell and subsequent large deposition of fission products on the drywell structures tend to over-predict the dose rate in the drywell significantly. The other calculations which assume an early leakage from the RPV to the drywell seem to predict the increase in the dose rate in the drywell too early, but in the lack of dose rate measurements before $60 \mathrm{~h}$ this is only an indication. The calculations which do not assume any direct release of fission products from the RPV to the drywell before $60 \mathrm{~h}$ under-estimate the dose rate in the drywell by a large extent. Based on the results, the dose rate measurements at around $60 \mathrm{~h}$ would agree with the analyses showing some $5 \%$ of cesium and iodine in the drywell at that time as a result of a direct transport of cesium and iodine from the reactor vessel to the drywell thereby indicating that there would have been a leakage between the RPV and the containment before the reactor vessel lower head failure.

Comparison of the analysis results with the suppression chamber CAMS shows that almost all the analyses over-estimate the dose rate in the suppression chamber. However, given the uncertainty in the analyses and the dose rate conversion, the agreement is reasonable. One reason for the over-estimation may be a different water level in the suppression chamber than assumed in the conversion factors. As the water level has a strong influence on the dose rate with a large fraction of fission products in the water, a difference in the water level might
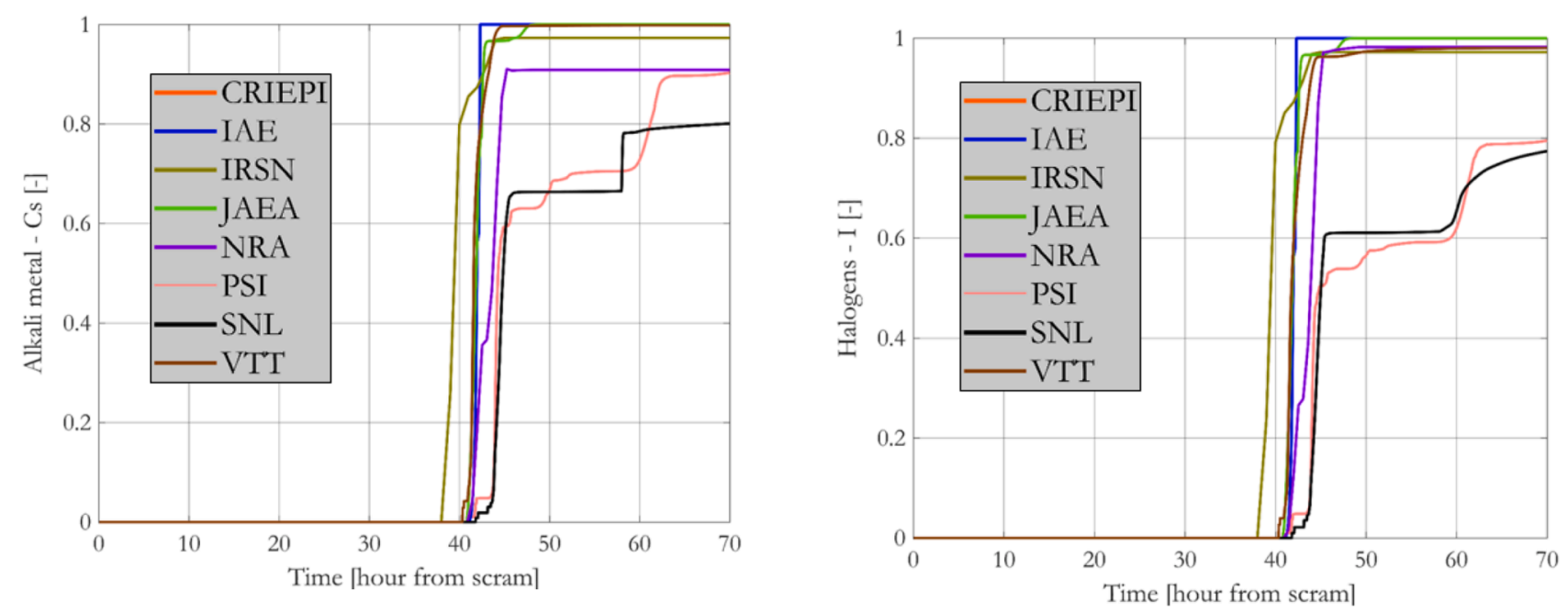

Fig. 8. Fraction of alkali metals and halogens released from the fuel. 

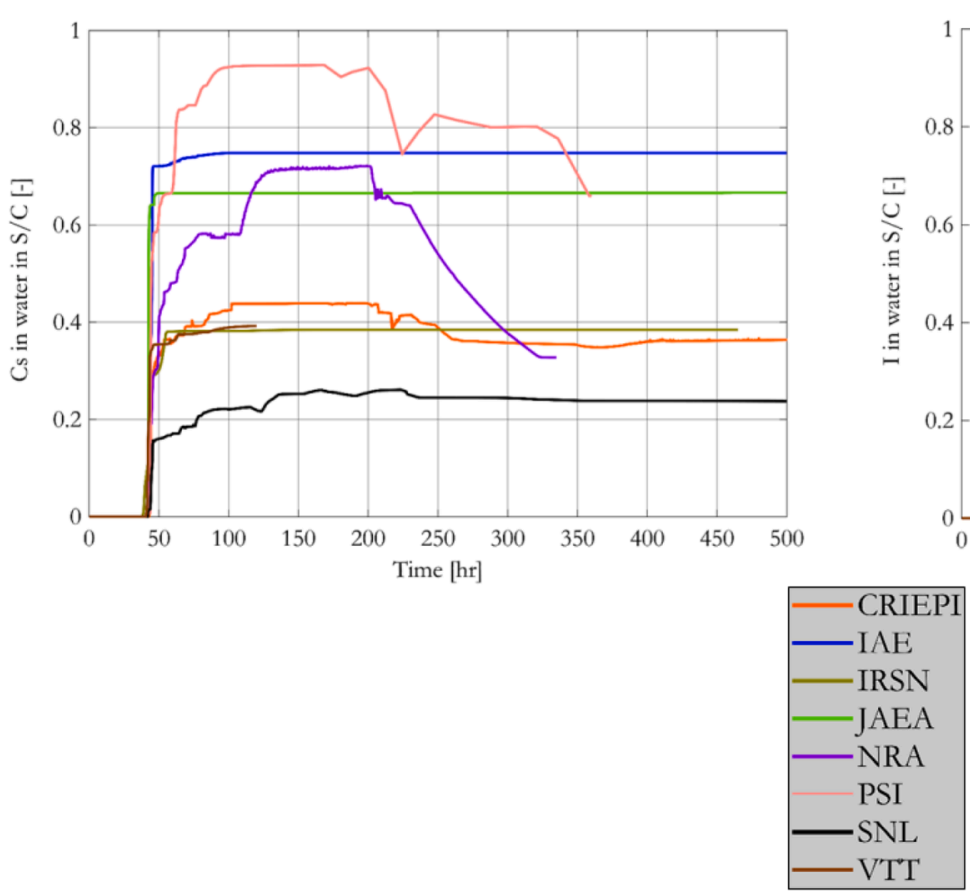

CRIEPI

SN

AEA

NRA

SNL

VTT

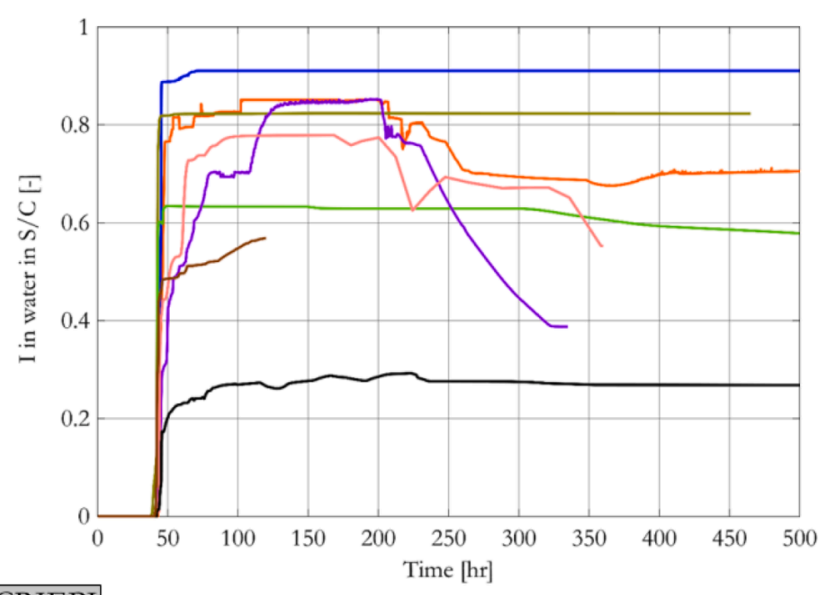

Fig. 9. Cesium and iodine in the suppression pool water.
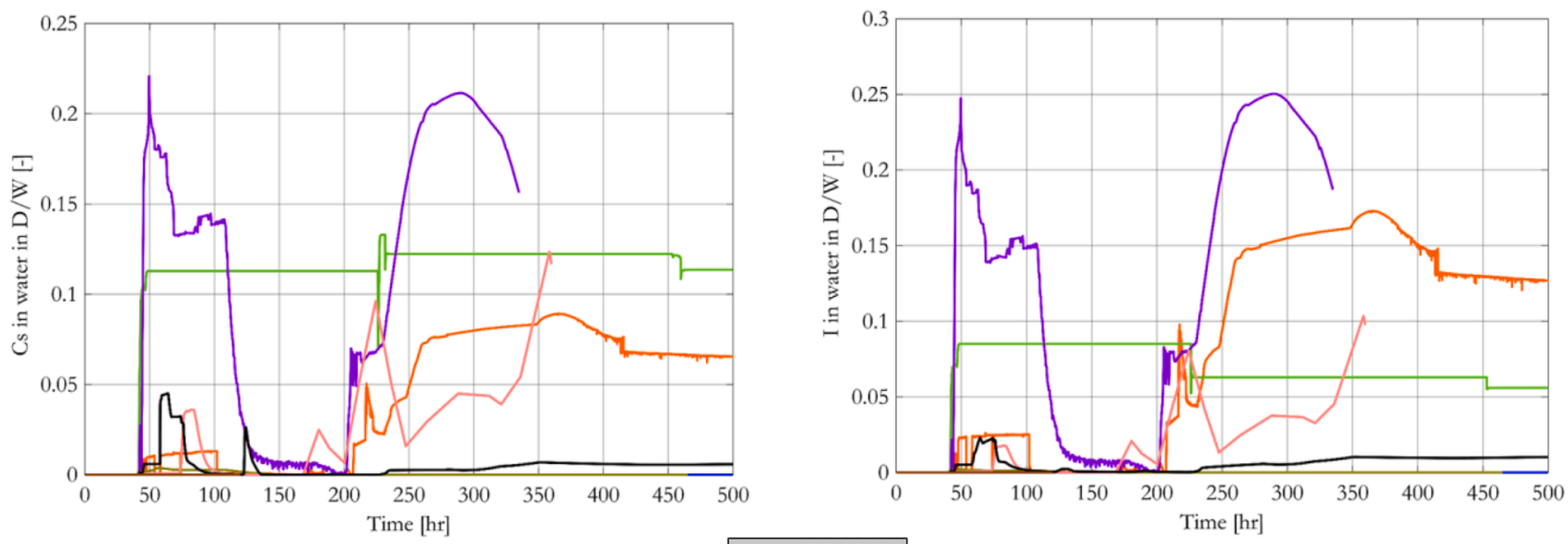

CRIEPI

IAE

IRSN

JAEA

NRA

PSI

SNL

VTT

Fig. 10. Cesium and iodine in the water in the drywell.

explain the relatively small discrepancy between the measured and analyzed dose rates. It is also possible that the dose rate in the suppression chamber is over-estimated because the pool scrubbing efficiency of the fission products was over-estimated in the analyses.

\subsection{Airborne fission product release to the environment}

In unit 3, the main fission product release to the atmosphere was calculated to take place during the containment vents and at the time of the hydrogen explosion. In addition, one calculation showed a continuous release of cesium and iodine through a drywell head flange leakage after the hydrogen explosion, and two calculations showed a considerable release at around $220 \mathrm{~h}$ in connection with the pressure increase in the containment at that time, Fig. 12.

About $80-100 \%$ of the noble gases were released to the atmosphere until the hydrogen explosion at $68 \mathrm{~h}$, hydrogen explosion included. Different calculations showed somewhat different timing of the release depending on the accident progression and the assumed transport path for the fission products. Two calculations showed continued release of noble gases after this time. Differences in the calculations are more 
Table 6

Distribution of cesium in unit 3 at the end of the calculation (\% of initial inventory).

\begin{tabular}{lrrrrrrc}
\hline & VTT & NRA & PSI & IRSN & JAEA & SNL & IAE \\
\hline Fuel debris & 0.2 & 11.7 & 4.7 & 2.7 & 0.0 & 4.1 & 0.0 \\
Reactor & 45.5 & 14.5 & 12.0 & 53.0 & 0.77 & 2.3 & 19.5 \\
Steam line & 5.2 & - & 2.4 & 0.0 & - & 0.1 & 0.03 \\
D/W & 6.4 & 8.7 & 9.0 & 0.8 & 14.9 & 57.1 & 0.07 \\
W/W & 39.2 & 23.8 & 61.3 & 39.0 & 76.0 & 23.1 & 75.1 \\
RB & 0.4 & 35.2 & 10.5 & 0.02 & 2.2 & 8.6 & 4.9 \\
Environment & 3.1 & 6.1 & 0.12 & 4.5 & 6.0 & 4.8 & 0.33 \\
\hline
\end{tabular}

Table 7

Distribution of iodine in unit 3 at the end of the calculation (\% of initial inventory).

\begin{tabular}{lrrrrrrl}
\hline & VTT & NRA & PSI & IRSN & JAEA & SNL & IAE \\
\hline Fuel debris & 1.4 & 1.6 & 26.4 & 3.0 & 0.00 & 10.6 & 0.00 \\
Reactor & 24.2 & 0.5 & 0.0 & 0.2 & 0.81 & 0.1 & 2.6 \\
Steam line & 5.5 & - & 0.4 & 0.0 & - & 0.1 & 0.03 \\
D/W & 7.0 & 12.0 & 8.1 & 0.4 & 20.2 & 39.6 & 0.06 \\
W/W & 56.7 & 31.5 & 55.3 & 83.3 & 73.0 & 31.1 & 89.4 \\
R/B & 0.7 & 45.8 & 9.5 & 0.0 & 3.2 & 8.51 & 6.8 \\
Environment & 4.0 & 8.6 & 0.33 & 13.1 & 2.8 & 10.0 & 1.0 \\
\hline
\end{tabular}

pronounced for the release of Cs and I, Fig. 12. Three calculations show a fast release of $3-5 \%$ of $\mathrm{Cs}$ to the atmosphere during the first containment vent which followed closely the reactor pressure vessel depressurization at $42 \mathrm{~h}$. The majority of the calculations assumed transport of Cs from the RPV to the containment through SRV with efficient scrubbing of Cs in the suppression pool, and a subsequent release of less than $0.5 \% \mathrm{Cs}$ until the hydrogen explosion at $68 \mathrm{~h}$.

The trend in the iodine release follows closely that of Cs, with the release fraction being on average slightly higher than that of Cs. One calculation shows a fast, high release of iodine during the first containment vent reaching a total of $13 \%$ of iodine released to the environment. Other calculations are divided into two groups, three calculations showing release of $4-9 \%$, and four calculations showing about $2 \%$ or less. As mentioned earlier, none of the calculations considered the transport of fission products to unit 4 reactor building. This would have reduced the release to the atmosphere due to deposition of fission products in the ventilation lines and in the unit 4 reactor building and delayed a fraction of the release due to transport to unit 4 .

Fig. 13 shows the comparison of cumulative release of cesium and iodine as calculated by the severe accident codes, and the releases estimated by the WSPEEDI and GRS codes based on environmental measurements and distribution in the atmosphere (Katata et al., 2015; Sonnenkalb et al., 2018). For the comparison, the time period 40-75 h after the accident initiation is used. This period was chosen because at this time, the major contribution to the fission product release is believed to have come from unit 3 . The major releases from unit 1 are believed to have taken place earlier as the major core degradation happened until 10-15 h from the accident initiation with the accompanied volatile fission product release during the containment vent at $24 \mathrm{~h}$. The water level in unit 2 was high until about $67 \mathrm{~h}$ when the coolant injection by RCIC failed. No significant releases from unit 2 occurred before $78 \mathrm{~h}$ at which time a rapid pressure increase was
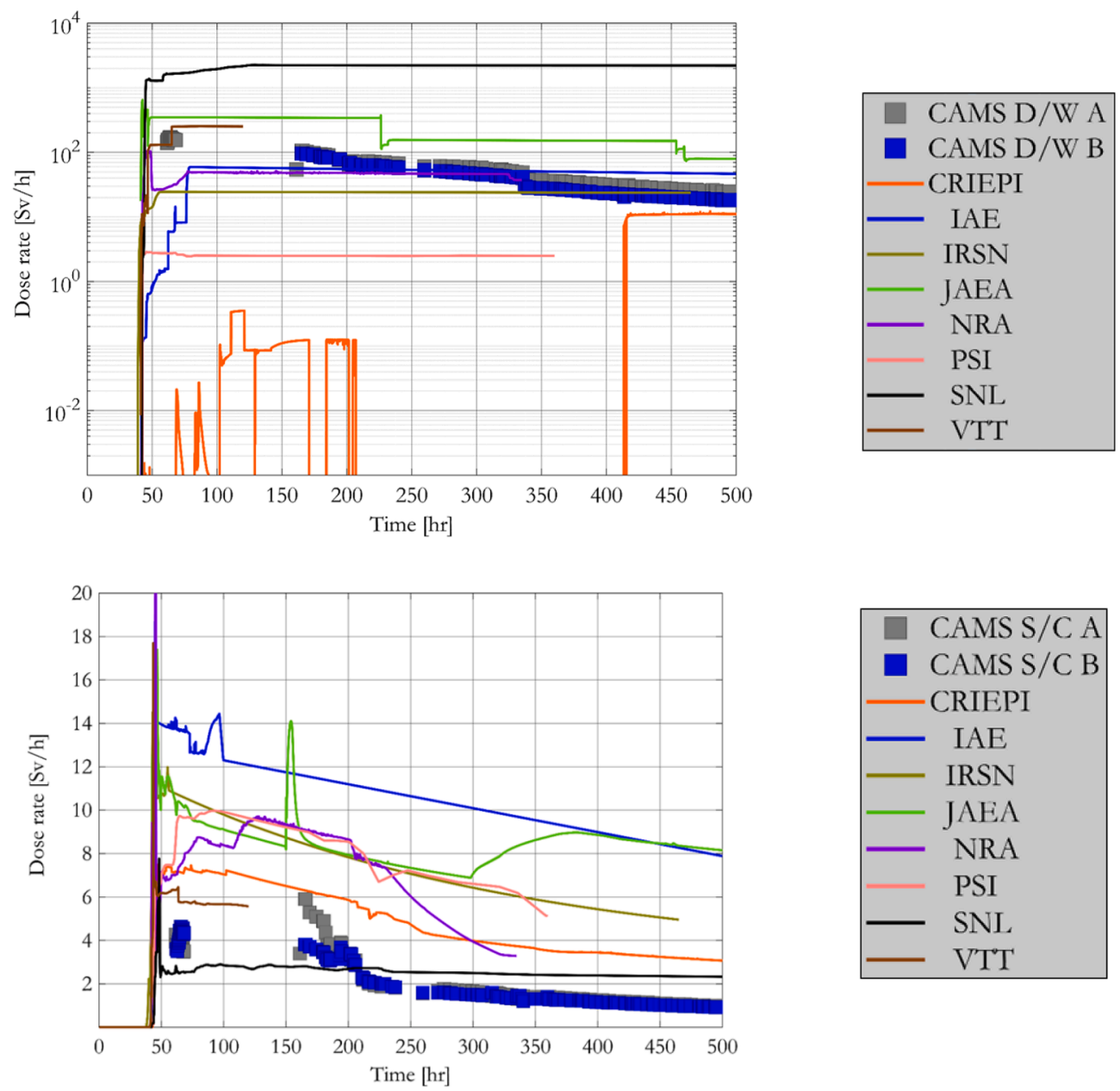

Fig. 11. Comparison of the analysis results with the CAMS measurement in the drywell (upper) and the suppression chamber (lower). 

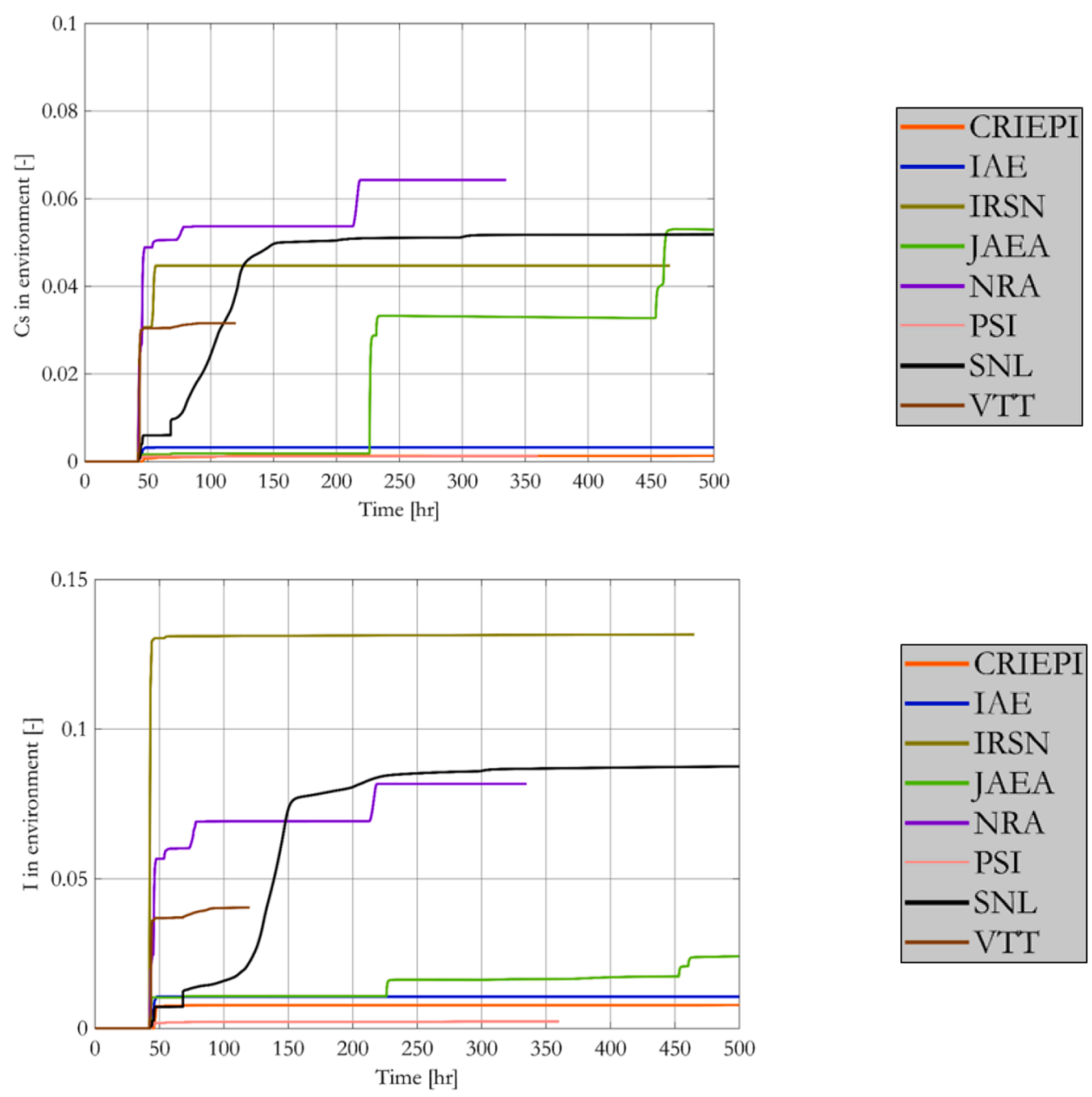

Fig. 12. Cesium and iodine release to the atmosphere.

observed in the reactor, and a high dose rate was measured at the main gate of the Fukushima Daiichi site.

The comparison shows that the calculations with a large early release of cesium and iodine tend to significantly over-estimate the release as compared to the data by WSPEEDI and the GRS code. The rest of the calculations show the same order of magnitude with the WSPEEDI and GRS code indicating that the release to the atmosphere should have been less than $0.5 \% \mathrm{Cs}$ initial inventory until the hydrogen explosion. Similar comparison for iodine shows that until the hydrogen explosion, approximately $2 \%$ of the initial inventory of iodine was likely to have been released to the atmosphere. It should be noted, however, that during the timeframe of the main release events in unit 3, i.e., the first containment vents and the hydrogen explosion, the dominant wind direction was towards the ocean, the wind thereby carrying the released fission products away from the land. This introduces significant uncertainty in the releases calculated by the inverse methods as the calculation for this time period relies on the measurement of activity in the samples of the ocean water.

\section{Final remarks}

The focus of the analyses in BSAF Phase- 2 was on the refinement of the accident progression analysis and on the fission product transport. In addition, it was shown that the severe accident analysis can be made for a period lasting for three weeks, something which was not attempted before these analyses. New insights were gained from these long-term analyses.
In unit 3, all the analyses showed that the reactor pressure vessel failed. A comparison with the containment CAMS indicated that a leakage or a failure of the reactor vessel took place most likely at around $60 \mathrm{~h}$ or earlier releasing fission products to the drywell. However, a very early large failure of the vessel seems to be unlikely. Most of the analyses showed that a large amount of corium and other materials was released from the reactor vessel to the containment. This is consistent with the most recent containment investigations by TEPCO which show a porous debris layer of up to $3 \mathrm{~m}$ thick on the containment floor. MCCI is predicted by most of the calculations, but its extent is still an open issue. The morphology of the debris layer indicates only limited MCCI.

The major calculated events of fission product release to the environment agree relatively well with the results given by atmospheric transport calculations by WSPEEDI and the GRS method. These events were related to the containment vents and the hydrogen explosion. With a large range of released amounts, the analyses with the relatively small release magnitude seem to agree best with the WSPEEDI results. Further releases by re-mobilization of fission products from surfaces and water are indicated by some of the analyses and cannot be excluded. Specifically, a large amount of contaminated water in the reactor building was indicated by several analyses. This water could have served as a source of continued iodine release. Also, potential release of fission products by remobilization of, e.g., Cs, from the surfaces by revaporization and resuspension should be addressed in future work. 

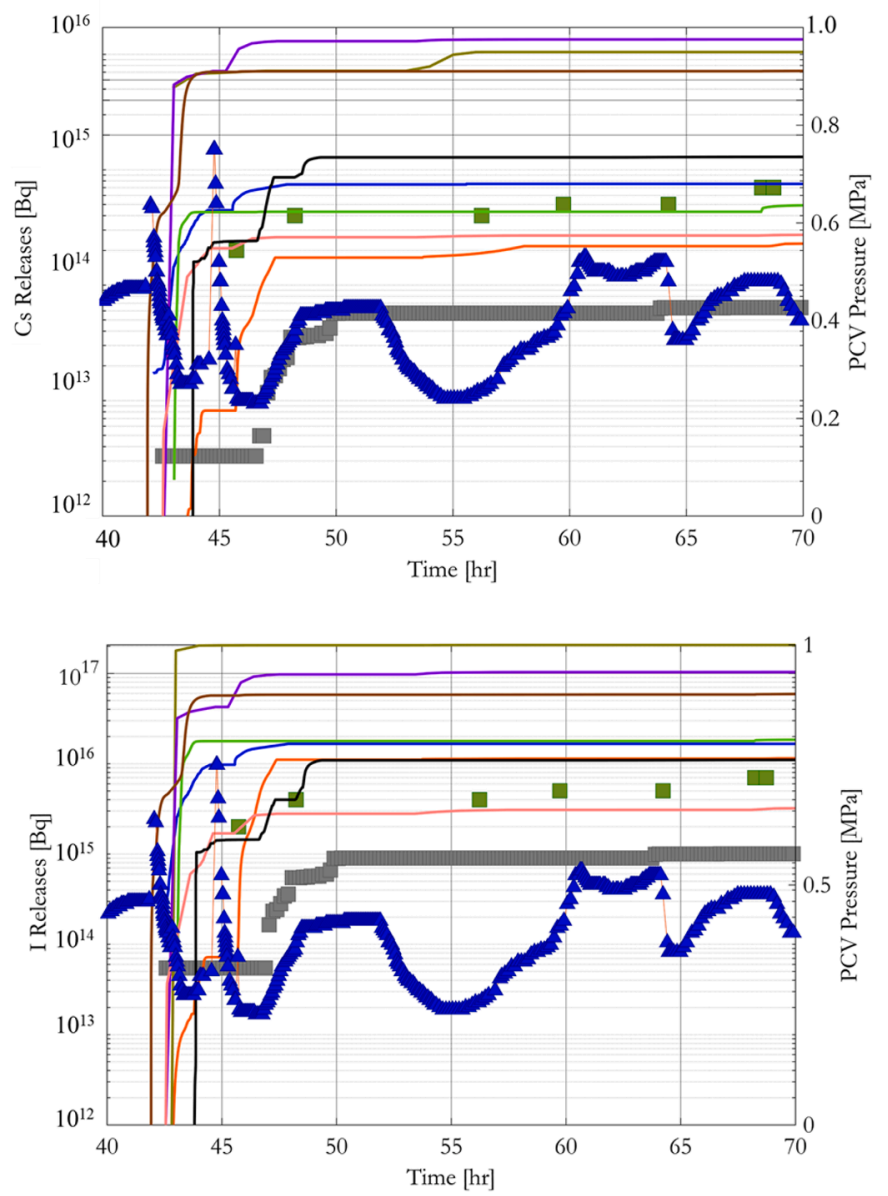

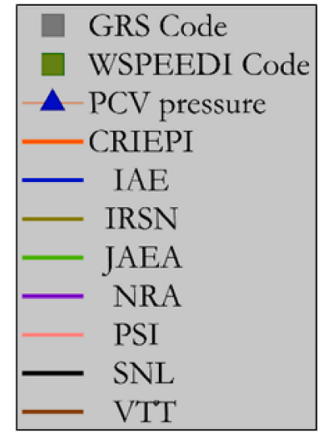

\begin{tabular}{|c|}
\hline$\square$ GRS Code \\
WSPEEDI Code \\
$\Delta$ PCV pressure \\
\hline CRIEPI \\
\hline IAE \\
\hline IRSN \\
\hline JAEA \\
\hline NRA \\
PSI \\
\hline SNL \\
\hline
\end{tabular}

Fig. 13. Comparison of cesium and iodine release versus WSPEEDI/GRS backwards calculation.

\section{CRediT authorship contribution statement}

T. Lind: Investigation, Writing - original draft, Writing - review \& editing. M. Pellegrini: Investigation, Formal analysis, Visualization, Writing - original draft. L.E. Herranz: Investigation, Writing - original draft. M. Sonnenkalb: Investigation, Writing - original draft. Y. Nishi: Investigation, Formal analysis. H. Tamaki: Investigation, Formal analysis. F. Cousin: Investigation, Formal analysis. L. Fernandez Moguel: Investigation, Formal analysis. N. Andrews: Investigation, Formal analysis. T. Sevon: Investigation, Formal analysis.

\section{Declaration of Competing Interest}

The authors declare that they have no known competing financial interests or personal relationships that could have appeared to influence the work reported in this paper.

\section{Acknowledgments}

The work was done within the OECD/NEA BSAF project, Phase 2, and the partners are acknowledged for the work.

\section{References}

BSAF, 2018. https://fdada.info/en/home2/ (restricted to members).

Cardoni, J., Gauntt, R., Kalinich, D., Phillips, J., 2014. MELCOR simulations of the severe accident at Fukushima Daiichi Unit 3. Nucl. Technol. Vol. 186.

Fernandez-Moguel, L., Rydl, A., Lind, T., 2019. Updated analysis of Fukushima unit 3 with MELCOR 2.1. Part 1: Thermal-hydraulic analysis. Ann. Nucl. Energy 123, 59-77.
Herranz, L.E., Pellegrini, M., Lind, T., Sonnenkalb, M., Godin-Jacqmin, L., López, C., Dolganov, K., Cousin, F., Tamaki, H., Kim, T.W., Hoshi, H., Andrews, N., Sevon, T., 2020. Overview and outcomes of the OECD/NEA benchmark study of the accident at the Fukushima Daiichi NPS (BSAF) Phase 2 - Results of severe accident analyses for Unit 1. Nucl. Eng. Design 369, 110849.

Katata, et al., 2015. Detailed source term estimation of the atmospheric release for the Fukushima Daiichi nuclear Power Station accident by coupling simulations of an atmospheric dispersion model with an improved deposition scheme and oceanic dispersion model. Atmos. Chem. Phys. 15, 1029-1070.

Nozaki, K. et al. 2017. Evaluation of inflow of venting gas of Fukushima Daiichi unit 3 into unit 4 using GOTHIC. Proceedings NURETH-17. 17th International Topical Meeting on Nuclear Reactor Thermal Hydraulics. Xi'an, Shaanxi, China, Sept. 3-8, 2017.

Pellegrini, M., Suzuki, H., Mizouchi, H., Naitoh, M., 2014. Early phase accident progression analysis of Fukushima Daiichi unit 3 by the SAMPSON Code. Nucl. Technol. 186.

Pellegrini, M., Herranz, L.E., Sonnenkalb, M., Lind, T., Maruyama, Y., Gauntt, R., Bixler, N., Morreale, A., Dolganov, K., Sevon, T., Jacquemain, D., Song, J.H., Nishi, Y., Mizokami, S., Lee, R., 2019a. Main findings, remaining uncertainties and lessons learned from the OECD, NEA BSAF project. Proceedings of NURETH-18, August 18-23 Portland, Oregon, USA.

Pellegrini, M., et al. 2019. Final Report of the OECD/NEA BSAF Project, Phase II, summary report.

Robb, K.R., Francis, M.W., Ott, L.J., 2014. Insight from Fukushima Daiichi Unit 3 investigations using MELCOR. Nucl. Technol. 186.

Rýdl, A., Fernandez Moguel, L., Lind, T., 2018. Modeling of aerosol fission product scrubbing in experiments and in integral severe accident scenarios. Nucl. Technol. https://doi.org/10.1080/00295450.2018.1511213, 16 p.

Sakamoto, Y., Tanaka, S., 1990. QAD-CGGP2 and G33-GP2: Revised Version of QADCGGP and G33-GP, JAERI-M 90-110. Japan Atomic Energy Research Institute (JAERI).

Sonnenkalb, M., Band, S., Richter, C., Sogalla, M., 2018. Unfallablauf- und Quelltermanalysen zu den Ereignissen in Fukushima im Rahmen des OECD/NEA BSAF-Projektes Phase II. GRS Rep. 485. ISBN 978-3-946607-69-4.

Sonnenkalb, M., Pellegrini, M., Herranz, L.E., Lind, T., Morreale, A.C., Kanda, K., Tamaki, H., Kim, S.I., Cousin, F., Fernandez Moguel, L., Andrews, N., Sevon, T., 2020. Overview and outcomes of the OECD/NEA benchmark study of the accident at the Fukushima Daiichi NPS (BSAF), phase 2 - Results of severe accident analyses for unit 2. Nucl. Eng. Design 369, 110840. 
TEPCO, 2014. Tokyo Electric Power Company, Inc., Evaluation of the situation of cores and containment vessels of Fukushima Daiichi Nuclear Power Station Units1 to 3 and examination into unsolved issues in the accident progression, Progress Report No. 2, Attachment 1 (Arrival times of tsunami at the Fukushima Daiichi Nuclear Power Station site), August 6, 2014.

TEPCO, 2017. https://www7.tepco.co.jp/responsibility/decommissioning/action/fuel_ debris/unit3-e.html. Accessed February 21, 2019.
The Damage and Accident Responses at the Fukushima Daiichi NPS and the Fukushima Daini NPS, http://www.cas.go.jp/jp/seisaku/icanps/eng/03IIfinal.pdf.

Yamanaka, Y., Mizokami, S., Watanabe, M., Honda, T., 2014. Update of the First TEPCO MAAP accident analysis of units 1, 2, and 3 at Fukushima Daiichi Nuclear Power Station. Nucl. Technol. 186 (2), 263-279. https://doi.org/10.13182/NT13-46 Link: https://doi.org/10.13182/NT13-46. 